\title{
The role of DNA damage and repair in decitabine-mediated apoptosis in multiple myeloma
}

\author{
Ken Maes ${ }^{1}$, Eva De Smedt ${ }^{1}$, Miguel Lemaire ${ }^{1}$, Hendrik De Raeve ${ }^{2}$, Eline Menu ${ }^{1}$, Els \\ Van Valckenborgh ${ }^{1}$, Steve McClue ${ }^{3}$, Karin Vanderkerken ${ }^{1, *}$ and Elke De Bruyne ${ }^{1, *}$ \\ ${ }^{1}$ Department of Hematology and Immunology-Myeloma Center Brussels, Vrije Universiteit Brussel, Brussels, Belgium; \\ 2 Department of Pathology, UZ Brussel, Vrije Universiteit Brussel, Brussels, Belgium; \\ 3 Oncology Translational Medicine, Janssen, Pharmaceutical Companies of Johnson \& Johnson, Buckinghamshire, United \\ Kingdom. \\ * These authors contributed equally \\ Correspondence to: Elke De Bruyne, email: eldebruy@vub.ac.be
}

Keywords: Multiple myeloma, DNA methyltransferase inhibitor, histone deacetylase inhibitor, DNA damage, DNA repair

Received: January 21, 2014

Accepted: March 21, 2014

Published: March 22, 2014

This is an open-access article distributed under the terms of the Creative Commons Attribution License, which permits unrestricted use, distribution, and reproduction in any medium, provided the original author and source are credited.

\section{ABSTRACT:}

DNA methyltransferase inhibitors (DNMTi) and histone deacetylase inhibitors (HDACi) are under investigation for the treatment of cancer, including the plasma cell malignancy multiple myeloma (MM). Evidence exists that DNA damage and repair contribute to the cytotoxicity mediated by the DNMTi decitabine. Here, we investigated the DNA damage response (DDR) induced by decitabine in MM using 4 human MM cell lines and the murine 5T33MM model. In addition, we explored how the HDACi JNJ-26481585 affects this DDR. Decitabine induced DNA damage (gamma-H2AX foci formation), followed by a G0/G1- or G2/M-phase arrest and caspase-mediated apoptosis. JNJ-26481585 enhanced the anti-MM effect of decitabine both in vitro and in vivo. As JNJ-26481585 did not enhance decitabine-mediated gamma-H2AX foci formation, we investigated the DNA repair response towards decitabine and/or JNJ-26481585. Decitabine augmented RAD51 foci formation (marker for homologous recombination (HR)) and/or 53BP1 foci formation (marker for non-homologous end joining (NHEJ)). Interestingly, JNJ-26481585 negatively affected basal or decitabineinduced RAD51 foci formation. Finally, B02 (RAD51 inhibitor) enhanced decitabinemediated apoptosis. Together, we report that decitabine-induced DNA damage stimulates HR and/or NHEJ. JNJ-26481585 negatively affects RAD51 foci formation, thereby providing an additional explanation for the combinatory effect between decitabine and JNJ-26481585.

\section{INTRODUCTION}

Multiple myeloma (MM) is a plasma cell malignancy characterized by accumulation of $\mathrm{MM}$ cells in the bone marrow (BM) [1]. Nowadays, patients receive induction therapy with different combinations of drugs including proteasome inhibitors, immunomodulatory agents, alkylators and corticosteroids based on risk stratification. Next, if eligible, patients undergo high dose chemotherapy followed by autologous stem cell transplantion and/or consolidation or maintenance therapy [2-8]. Even though significant prolongation of overall survival is accomplished, the vast majority of patients relapses and develops non-responsive disease, demonstrating the further need for novel drugs and new therapeutic approaches.

Epigenetic modulating agents have shown considerable preclinical and clinical efficacy in hematological malignancies $[9,10]$. The cytidine analog 5 -aza-2'deoxycytidine or decitabine is such an epigenetic modulating agent acting as an irreversible inhibitor of DNA methyltransferases (DNMTi). Upon replication, decitabine is incorporated into DNA thereby trapping DNMT enzymes in a covalent way resulting in DNA- 
protein adducts [11]. The cytotoxic effects of decitabine can then be explained by two modes of action. First, trapping of DNMT enzymes leads to depletion of DNMT and the cell loses its ability to methylate DNA. The result is a genome-wide loss of methylation leading to re-activation of silenced genes, genomic instability and related anti-tumor effects. Second, the formation of DNAprotein adducts results in the activation of a DNA damage response (DDR) that can ultimately result in apoptosis.

The activation of a DDR is initiated by recognition of DNA lesions followed by cell cycle arrest and recruitment of DNA repair proteins mediating repair of the lesion. Depending on the type of lesion, different repair pathways are elicited. Double strand break repair is mediated by homologous recombination (HR) or nonhomologous end joining (NHEJ). NHEJ takes place throughout all phases of the cell cycle and is considered to be error-prone. In contrast, HR takes place during S- and G2/M-phase and is dependent on the sister chromatid and considered to be more error-free. Consequently, during S- and G2/M-phase, the balance between NHEJ and HR determines which pathway will be used to repair DNA lesions [12]. Considering DNA repair in MM, it is thought that abnormal DNA repair pathways play an important role in the disease onset, progression and occurrence of resistance. This abnormal DNA repair is the result of (epigenetic) dysregulation and/or polymorphisms of genes involved in DNA repair and an accumulation of chromosomal abnormalities in MM [13]. For example, several polymorphisms in genes involved in NHEJ have been described in MM. In addition, NHEJ activity seems aberrant in MM cell lines and this influences the response towards ionizing radiation [14]. Furthermore, the activity of HR appears increased in MM [15].

Only a few studies have addressed the involvement of DNA repair in response to decitabine. In mammalian cells, HR has been implicated in tolerance towards DNA protein cross-links [16]. Recently, it was demonstrated that in Chinese hamster ovary cells, decitabine caused DNA lesions and triggered Fanconi Anemia-dependent HR. Fanconi Anemia-defective cells appeared to be more sensitive to decitabine compared to Fanconi Anemia-wildtype cells, due to the predominance of error-prone NHEJ in Fanconi Anemia-defective cells resulting into cytotoxic chromosome aberrations [17]. However, HR and NHEJ activity upon decitabine exposure have not yet been adequately addressed in MM.

The histone deacetylase inhibitors (HDACi) form another class of epigenetic modulating agents with considerable pre-clinical anti-MM activity [10]. Furthermore, HDACi showed beneficial effects in combination with conventional agents in relapsed MM patients [18, 19]. Today, several links between acetylation, HDACi and DNA repair mechanisms have been established. It is realized now that protein acetylation influences the recruitment and expression of DNA repair proteins and therefore can be used as a target to modify DNA repair pathways in response to different DNA damaging agents [20].

There has been considerable interest in combining DNMTi and HDACi to enhance the anti-tumor effects of both agents [21]. The mechanism of action involves a broad spectrum of effects that range from true epigenetic changes, chromatin- and DNA-related effects, disruption of the acetylome and micro-environmental effects $[10,22]$. Previous studies on these combinations demonstrated alterations in gene expression that may correlate with an enhanced apoptotic effect and direct modulation of downstream apoptotic effectors [23-28]. Alternatively, the combinatory effects of decitabine and HDACi could be related to the DDR and modulation of the DNA repair pathways. So it would be interesting to investigate which DNA repair pathways are activated upon decitabine treatment in MM and how HDACi can affect this. Therefore, we investigated the anti-MM effects of decitabine alone and in combination with the HDACi JNJ-26481585 (JNJ-585) using human myeloma cell lines (HMCLs) and the syngeneic murine 5T33MM model and tried to unravel the underlying mechanisms with a focus on cell cycle regulation and DNA damage/repair.

\section{RESULTS}

\section{Decitabine showed anti-MM effects both in vitro and in vivo}

To evaluate the anti-MM effects of decitabine, we treated 4 HMCLs with different concentrations of decitabine and determined the percentage apoptotic cells. OPM-2 and NCI-H929 cells showed significant induction of apoptosis from 3 days on, while RPMI-8226 and JJN3 cells were more sensitive showing increased apoptosis already after 2 days (Figure 1A). Both in OPM2 and RPMI-8226 cells, western blot analysis revealed a simultaneous increase in cleavage of caspase-9, -8 and -3, PARP-1 and the anti-apoptotic protein MCL-1 (Figure 1B). In addition, decitabine upregulated the proapoptotic protein BIM (all isoforms) in both cell lines (Figure 1B) and quantitative real-time PCR revealed that this is transcriptionally mediated (Supplementary Figure S1). To determine the potential therapeutic effects of decitabine in vivo, we treated 5T33MM inoculated mice with increasing doses of decitabine. Tumor load in the $\mathrm{BM}$ and serum M-spike were significantly lower for all decitabine treatment groups (Figure 1C). Of note, we detected no significant weight loss of the mice indicating no major toxicity (data not shown). We also performed a similar experiment in a survival setup. 5T33MM mice treated with decitabine had significant higher survival rates when compared to vehicle treated mice: 29 and 36 
days for respectively $0.2 \mathrm{mg} / \mathrm{kg}$ decitabine and $0.5 \mathrm{mg} / \mathrm{kg}$ decitabine versus 25 days for vehicles (Figure 1D).

\section{Decitabine negatively affects cell cycle progression}

To investigate the mechanisms underlying the anti-MM activity of decitabine, we next determined how decitabine influences cell cycle progression in HMCLs. Therefore, we assessed DNA content together with BrdU-incorporation at timepoints when there is minimal induction of apoptosis. At control conditions, BrdU incorporation was higher for RPMI-8226 and JJN3 cells compared to OPM-2 and NCI-H929 cells. For all cell lines tested, we observed a significant decrease of BrdU incorporation upon treatment with decitabine compared to control (Figure 2A). Concordantly, DNA content analysis revealed that all cell lines showed a decrease of cells in the S-phase (Figure 2B). OPM-2, NCI-H929 and JJN3 cells accumulated all in G0/G1-phase, while RPMI-8226 cells slightly accumulated in G2/M-phase (Figure 2B). As the CDK-inhibitor p27 is known to regulate both G1 and G2 checkpoints [32], we next evaluated p27 expression and its upstream regulator SKP-2. Decitabine treatment simultaneously upregulated p27 and decreased SKP-2 expression in both OPM-2 and RPMI-8226 cells (Figure $2 \mathrm{C})$.

\section{Decitabine induces formation of gamma-H2AX foci}

The decitabine-mediated effects on cell cycle progression indicate an activation of cell cycle checkpoints in response to DNA damage. Therefore, we assessed whether decitabine could induce a DNA damage response in HMCLs. For this, we treated OPM-2 and RPMI-8226
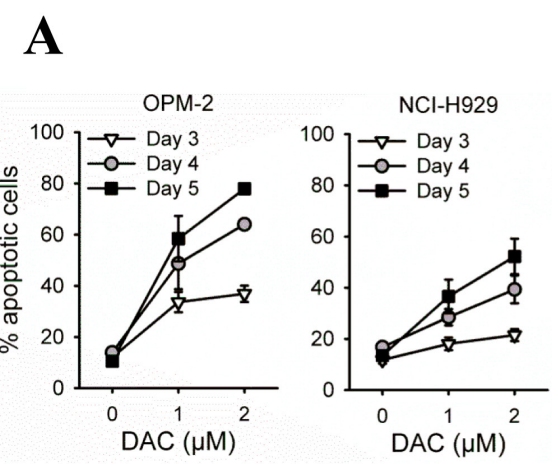

C

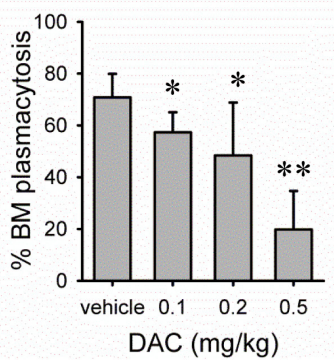

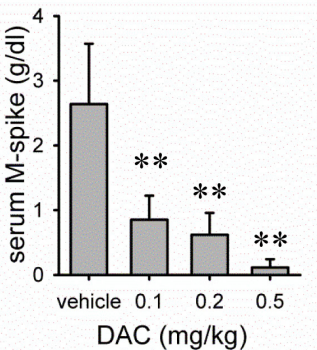

$\mathrm{DAC}(\mathrm{mg} / \mathrm{kg})$
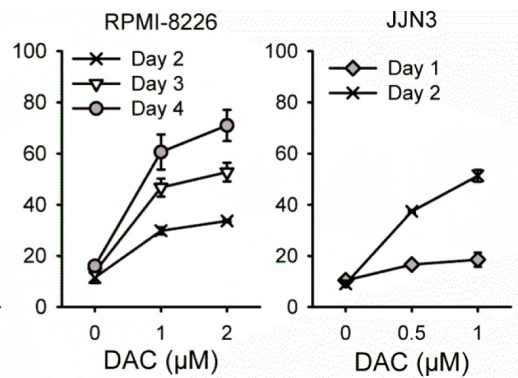

\section{D}

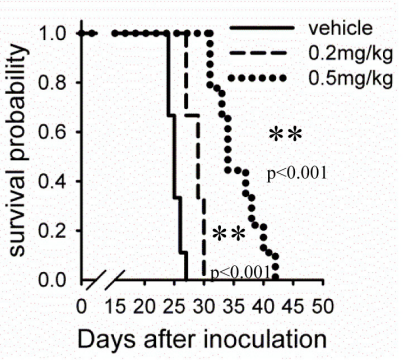

B
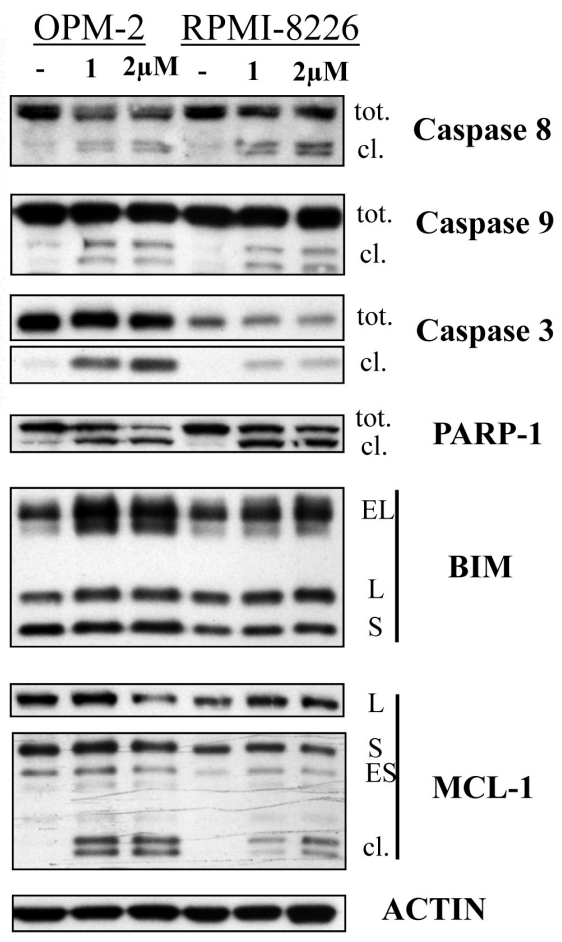

Figure 1: Decitabine has in vitro and in vivo anti-MM activity. A: Cells were treated with different concentrations of decitabine (DAC) for indicated timepoints. Apoptosis was determined by flow cytometry using AnnexinV-FITC/7'AAD staining. Apoptotic cell percentage is the sum of annexinV+ and AnnexinV+/7' $\mathrm{AAD}+$ cell percentage. Dots and error bars represent mean and $\mathrm{SD}$ of 3 independent experiments. B: Cells were treated for 4 days. Total protein lysates were analyzed by western blot for the presence of caspase- $9,-8,-3$, PARP-1, BIM and MCL-1. tot. = total; cl. = cleaved. C: C57BL/KaLwRij mice were inoculated with 5T33MM cells and treated from day 1. The experiment was terminated when the first mice showed signs of morbidity. Treatment groups were vehicle $(n=5), 0.1(n=6), 0.2(n=5)$ and $0.5 \mathrm{mpk}$ decitabine $(\mathrm{n}=6)$. After sacrification, $\mathrm{BM}$ from hind legs was isolated. Cytospins were made and stained with May GrünwaldGiemsa. BM plasmacytosis was quantified by manual counting. Total blood was collected and the serum M-spike was measured using serum electrophoresis. * indicates $p<0.05$ and $* *$ indicates $p<0.001$ vs. vehicle. D: Mice were treated 1 day after inoculation with 5T33MM cells. Treatment groups were vehicle $(\mathrm{n}=9), 0.2(\mathrm{n}=9)$ and $0.5 \mathrm{mpk}$ decitabine $(\mathrm{n}=9)$. Mice were sacrified individually when showing signs of morbidity. Kaplan-Meier curves were constructed and significance was evaluated by a log-rank test. 
cells with decitabine for 24 and 48 hours and analyzed gamma-H2AX foci formation, a widely used DNA damage marker. The alkylator melphalan was included as a positive control. We observed that both cell lines already have around 15 to $25 \%$ gamma-H2AX positive cells in control conditions. After decitabine treatment, the percentages of gamma-H2AX positive cells significantly increased in both OPM-2 and RPMI-8226 cells compared to control and this already after 24 hours (Figure 3A, B). Compared to melphalan, decitabine led to lower percentages of gamma-H2AX positive cells.

\section{The HDAC inhibitor JNJ-26481585 enhances decitabine-mediated anti-MM effects}

Next, we tried to augment decitabine-mediated cell death by combining decitabine with a histone deacetylase inhibitor (HDACi), namely JNJ-26481585 (JNJ-585). Previously, we have proven that JNJ-585 has potent anti-MM effects both in vitro and in vivo [31]. To assess whether decitabine and JNJ-585 have synergistic anti-MM effects, we treated OPM-2 cells with different doses of each agent alone and in combination for 72 hours. Using the Cell Titer-Glo viability assay, we demonstrated a synergistic interaction between both agents as evidenced by combination indexes well below 1 (Supplementary Figure S2). Next, we tested whether JNJ-585 could enhance decitabine-mediated apoptosis using suboptimal doses of both agents. As shown in Figure 4, apoptosis was further enhanced in all cell lines tested and for OPM2 and RPMI-8226 cells this was also associated with combinatory effects on cleavage of caspases, PARP-1 and MCL-1 (Figure 4A, B). Simultaneously, we also evaluated the effect of the combination on cell cycle progression.

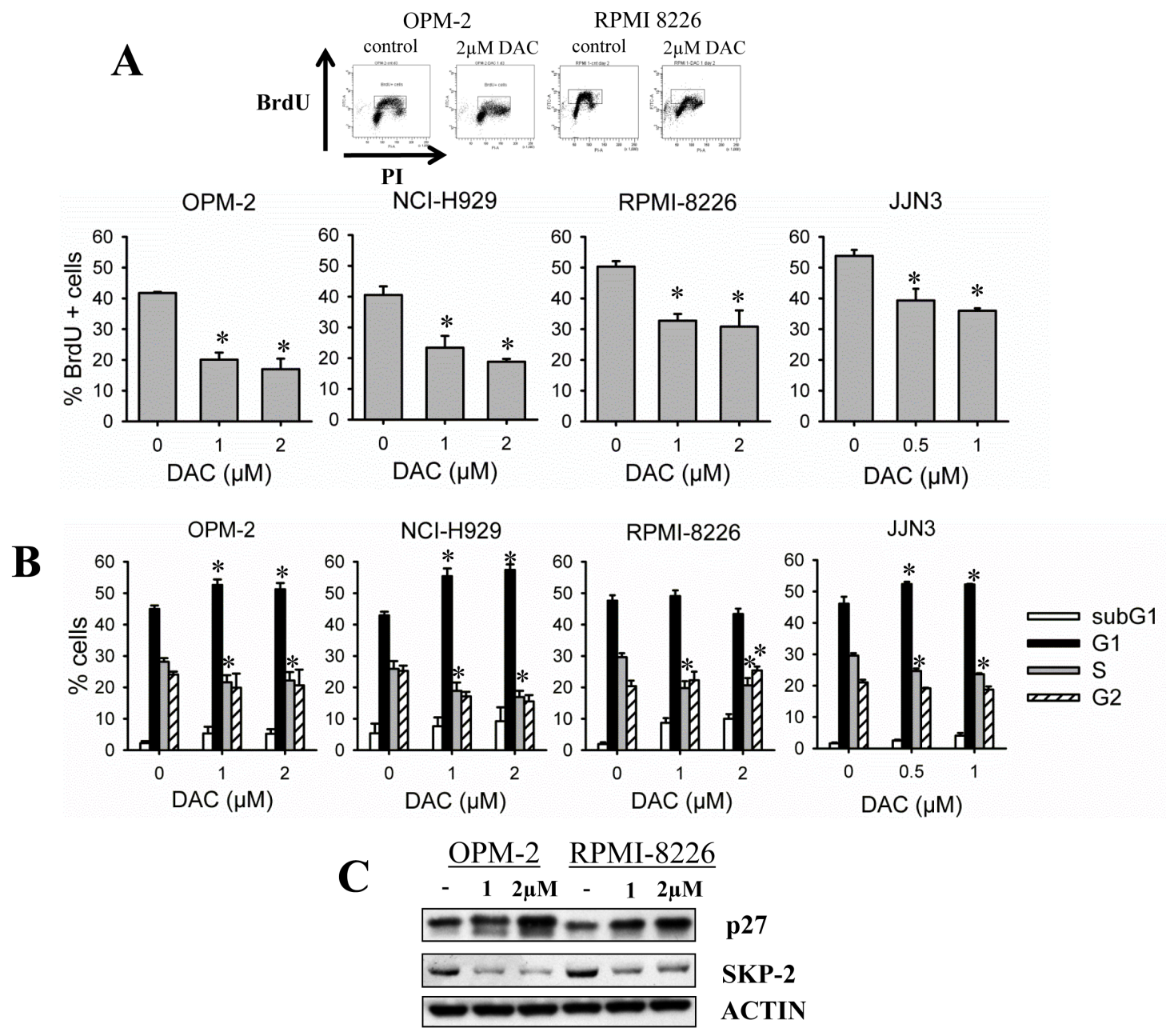

Figure 2: Decitabine negatively affects cell cycle progression. A-B: OPM-2, NCI-H929, RPMI-8226 and JJN3 cells were treated with decitabine (DAC) for respectively 3, 3, 2 and 1 day(s). A: 2 hours prior to harvest, BrdU was added to the culture wells. Next, cells were stained with PI and anti-BrdU-FITC and analyzed by flow cytometry for DNA content and BrdU incorporation. Top: flow cytometry profiles of OPM-2 and RPMI-8226 cells. Bottom: Percentage of BrdU positive cells. B: Cell cycle profiles based on DNA content were obtained from PI histograms. Bars and error bars are mean and SD of 3 independent experiments. * indicates p<0.05 compared to control. C: Cells were treated for 3 days and total protein lysates were analyzed by western blot for the presence of p27 and SKP-2. ACTIN was used as loading control. 
JNJ-585 alone induced a clear G0/G1-phase arrest in all cell lines, though less pronounced in RPMI-8226 cells (Figure 4C). In OPM-2 and JJN3 cells, the G0/G1-phase arrest remained after combination treatment, while in RPMI-8226 cells a clear and significant increase of cells in the subG1-phase was observed compared to single agents (Figure 4C). To confirm the in vitro data, we then tested if JNJ-585 could potentiate decitabine-mediated effects in the 5T33MM model. Indeed, the combination of a suboptimal dose of decitabine and JNJ-585 significantly augmented the effects of decitabine on tumor progression and survival (Figure 4D, E).

\section{JNJ-585 alters the DNA repair response towards decitabine-induced DNA damage}

We next investigated the effects of JNJ585 on decitabine-mediated DNA damage. Using immunofluorescence analysis, we found that suboptimal doses of JNJ-585 did not change the baseline percentage of gamma-H2AX positive cells in OPM-2 and RPMI8226 cells (Figure 5A). In addition, the combination
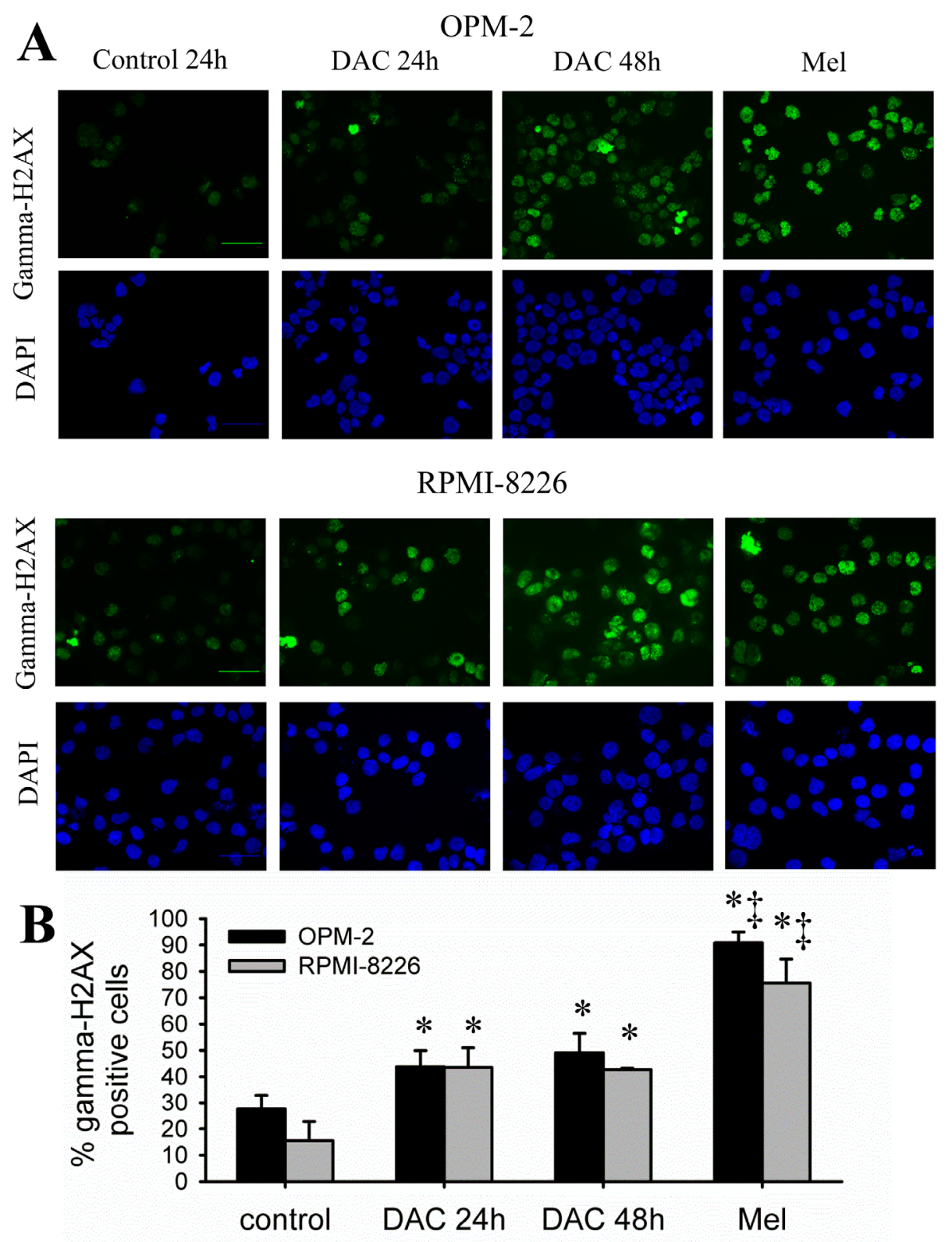

Figure 3: Decitabine induces gamma-H2AX foci formation. A-B: Cells were treated with decitabine (DAC; $1 \mu \mathrm{M})$ for 24 and 48 hours. Melphalan $(5 \mu \mathrm{M}, 24$ hours) was used as positive control. Next, cytospins were made and stained for gamma-H2AX. A: Immunofluorescent pictures of OPM-2 and RPMI-8226 cells after staining for gamma-H2AX and DAPI. Scale bar $=50 \mu \mathrm{m}$. B: Quantification of the gamma-H2AX foci using ImageJ macro PZ-FociEZ. At least 100 nuclei were analyzed and nuclei with at least 10 foci were scored as positive. Data are shown as mean $\pm \mathrm{SD}$ of 3 experiments. * indicates $\mathrm{p}<0.05$ compared to basal conditions. $\ddagger$ indicates $\mathrm{p}<0.05$ compared to decitabine. 
showed similar but not additional numbers of gamma$\mathrm{H} 2 \mathrm{AX}$ positive cells compared to decitabine (Figure 5A). This suggests that decitabine-induced DNA damage is not enhanced by JNJ-585. Next, we hypothesized that JNJ-585 might alter the DNA repair response towards decitabine, thereby enhancing the cytotoxicity of the DNA damage induced by decitabine. As previously mentioned, double strand break repair is involved in decitabine-mediated DNA lesions [16, 17]. Therefore, we analyzed the contribution of $\mathrm{HR}$ and NHEJ by evaluating the presence of respectively RAD51 and 53BP1 foci. Both OPM-2 and RPMI-8226 cells already showed RAD51 and 53BP1 foci formation in basal conditions (Figure 5B and Supplementary Figure S3-
S6). Decitabine alone significantly increased the number of 53BP1 positive cells in both OPM-2 and RPMI-8226 cells, while RAD51 positive cells were increased only in RPMI-8226 cells (Figure 5B and Supplementary Figure S3-S6). Interestingly, JNJ-585 alone did not alter the percentage of RAD51 positive cells compared to control conditions in RPMI-8226 cells. However, the increase in RAD51 positivity by decitabine was completely abrogated by JNJ-585 (Figure 5B and Supplementary Figure S3-S6). Moreover, in OPM-2 cells, JNJ-585 even decreased the baseline presence of RAD51 foci and this was even more pronounced in the combination. Although significance was not reached, JNJ-585 slightly increased the formation of 53BP1 foci in both cell lines (Figure
A
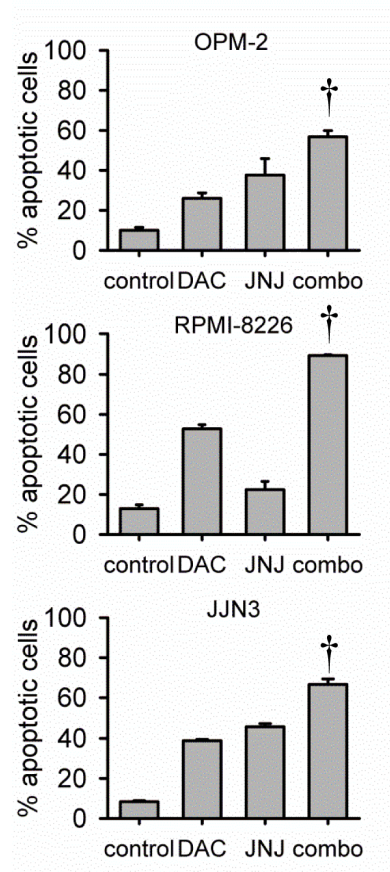

B

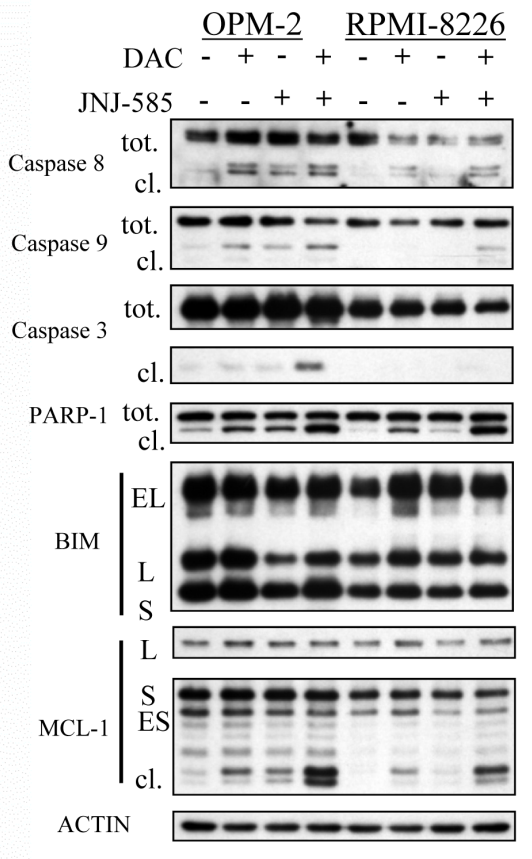

C
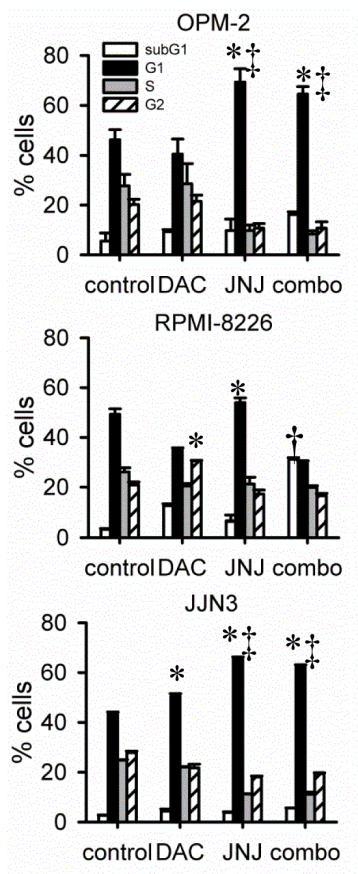

D
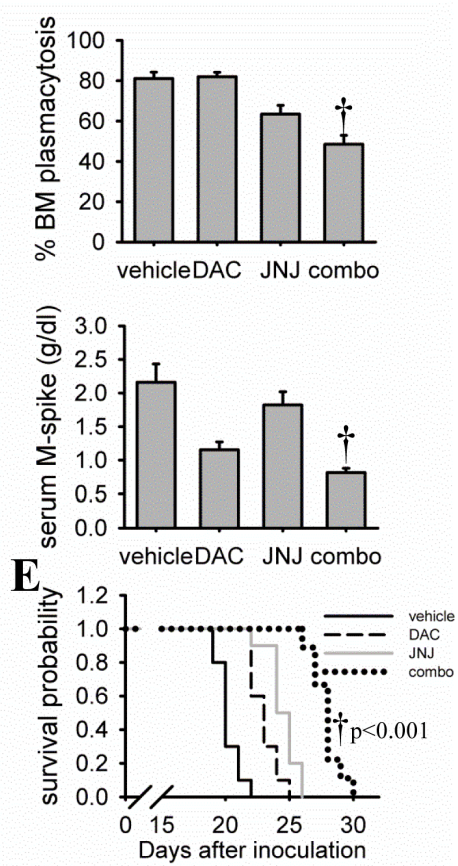

Figure 4: JNJ-585 enhances decitabine-mediated anti-MM effects. A-C: Cells were treated with decitabine (DAC) and/or JNJ-585 for 3 days (2 days for JJN3) (A) or 2 days ( 1 day for JJN3) (B, C). Doses used for OPM-2 were $1 \mu$ M decitabine and 2.5nM JNJ585; for RPMI-8226 $1 \mu \mathrm{M}$ decitabine and $5 \mathrm{nM}$ JNJ-585; for JJN3 $0.5 \mu \mathrm{M}$ decitabine and 10nM JNJ-585. A: Apoptosis was determined by flow cytometry using AnnexinV-FITC/7'AAD staining. Apoptotic cell percentage is the sum of annexinV+ and AnnexinV+/7'AAD + cell percentage. Bars and error bars are mean $\pm \mathrm{SD}$ of 3 experiments. B: Total protein lysates were subjected to western blot analysis for the expression of caspase-9, -8, -3, PARP-1, BIM and MCL-1. ACTIN was used as loading control. C: Samples were stained with PI and cell cycle profiles based on DNA content were obtained by flow cytometry. Bars and error bars are mean \pm SD of 3 experiments. D: C57BL/ KaLwRij mice were inoculated with 5T33MM cells and treated from day 1 . The experiment was terminated upon first signs of morbidity of the mice. Treatment groups were vehicle $(n=9), 0.2 \mathrm{mpk}$ decitabine $(n=9), 1.5 \mathrm{mpk} J \mathrm{NJ}-585(\mathrm{n}=9)$ or the combination $(\mathrm{n}=9)$. After sacrification, BM from hind legs was isolated. Cytospins were stained with May Grünwald-Giemsa and BM plasmacytosis was quantified by manual counting. Total blood was collected and the serum M-spike was measured using serum electrophoresis. E: Mice were treated 1 day after inoculation with purified 5T33MM cells. Treatment groups were as follows: vehicle $(\mathrm{n}=10), 0.2 \mathrm{mpk}$ decitabine $(\mathrm{n}=10), 1.5 \mathrm{mpk}$ JNJ-585 ( $\mathrm{n}=10)$ and the combination $(\mathrm{n}=9)$. Mice were sacrified individually when showing signs of morbidity. Kaplan-Meier curves were constructed and significance was evaluated by a log-rank test. * indicates $\mathrm{p}<0.05$ compared to control. $\$$ indicates $\mathrm{p}<0.05$ compared to decitabine. $\uparrow$ indicates $p<0.05$ vs. single agents. 
5B and Supplementary Figure S3-S6). The combination increased 53BP1 foci formation to a similar extent as decitabine. We next evaluated whether JNJ-585 could modulate expression of the HR-related genes RAD51, BRCA1 and BRCA2. Quantitative real-time PCR revealed that JNJ-585 could decrease the expression of RAD51 in both RPMI-8226 and OPM-2 cells. In addition, BRCA2 expression was downregulated in OPM-2 cells. There was also tendency for downregulation of BRCA1 expression in OPM-2 cells but significance was not reached (Figure 5C).

\section{Targeting DNA repair pathways appears useful in combination with decitabine}

The above experiments indicate that by targeting DNA repair responses, the cytotoxic effects of decitabine might be enhanced. Here, we chose to target RAD51 and PARP1/2 by respectively B02 and ABT-888. B02 is a specific RAD51 inhibitor that has not been used in MM or related disorders $[33,34]$, while ABT- 888 (Veliparib) is a PARP1/2 inhibitor [35]. B02 alone was cytotoxic in both OPM-2 and RPMI-8226 cells as evidenced by an increased percentage of apoptotic cells while ABT-888 alone did not
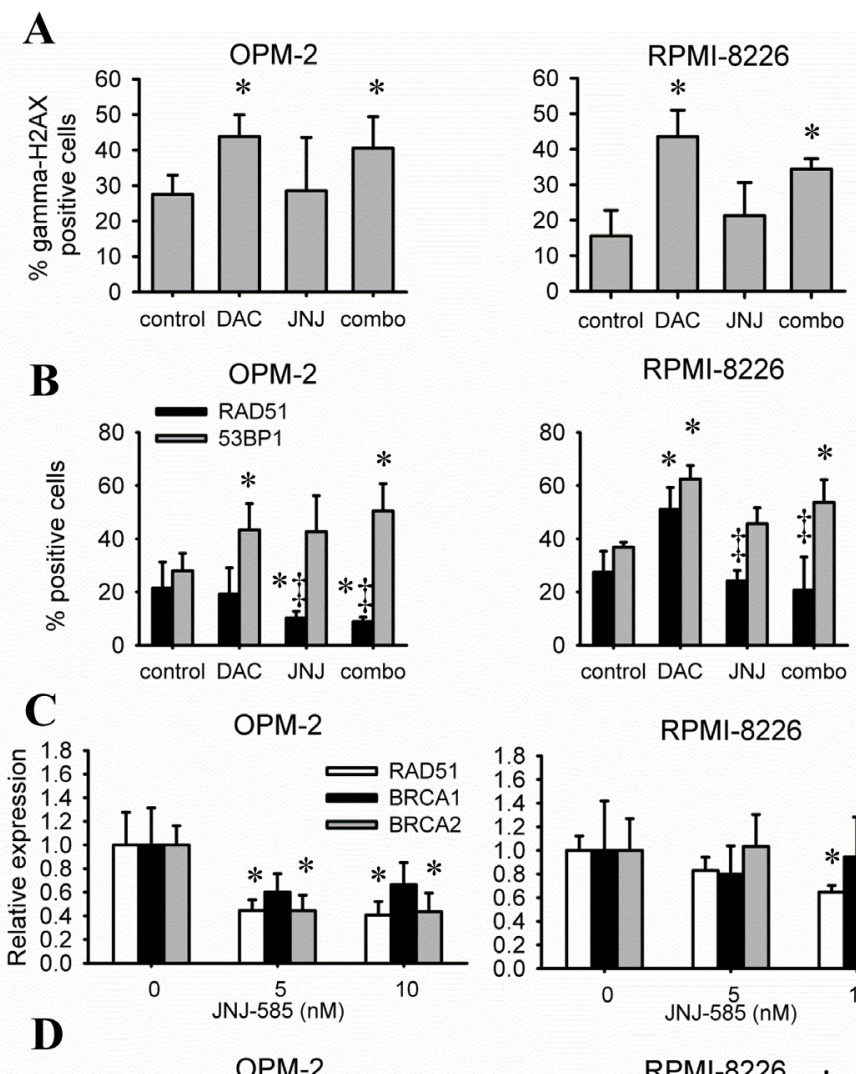

RPMI-8226
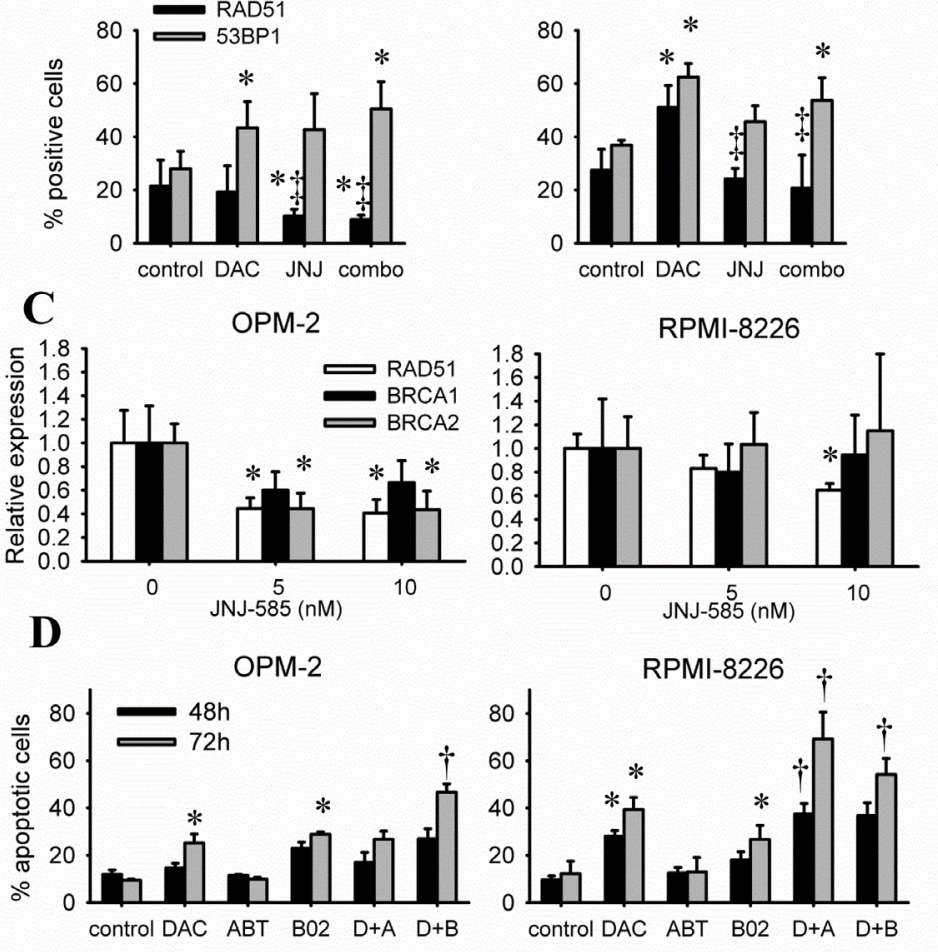

Figure 5: JNJ-585 affects the repair response elicited by decitabine. A-B: Cells were treated with decitabine (DAC) and/or JNJ-585 for 1 day. Doses for OPM-2 were $1 \mu \mathrm{M}$ decitabine and 2.5nM JNJ-585; for RPMI-8226 $1 \mu \mathrm{M}$ decitabine and 5nM JNJ-585. Next, cytospins were made and stained for gamma-H2AX (A), RAD51 and 53BP1 (B). Images were quantified using ImageJ PZFociEZ plugin. A: Quantification of gamma-H2AX foci. B: Quantification of RAD51 and 53BP1 foci. At least 100 nuclei were analyzed and nuclei with at least 10 foci were scored as positive. C: Cells were treated with JNJ-585 for 1 day. Samples were processed and used for qRT-PCR to analyze expression of RAD51, BRCA1 and BRCA2. ABL-1 was used as housekeeping gene. D: Cells were treated with decitabine $(1 \mu \mathrm{M})$ and/or B02 $(10 \mu \mathrm{M})$ or ABT-888 $(10 \mu \mathrm{M})$ for 2 or 3 days. Next, apoptosis was determined by flow cytometry using AnnexinV-FITC/7'AAD staining. Apoptotic cell percentage is the sum of annexinV+ and AnnexinV+/7'AAD + cell percentage. Data is shown as mean $\pm \mathrm{SD}$ of 3 experiments. * indicates $\mathrm{p}<0.05$ compared to untreated conditions. $\$$ indicates $\mathrm{p}<0.05$ compared to decitabine. $\uparrow$ indicates $\mathrm{p}<0.05$ compared to single agents. 
show any cytotoxicity (Figure 5D). Co-treatment of cells with B02 sensitized both OPM-2 and RPMI-8226 cells to decitabine as evidenced by significantly more apoptosis compared to single agents (Figure 5D). Co-treatment with ABT-888 also sensitized RPMI-8226 cells, but not OPM-2 cells, to decitabine (Figure 5D).

\section{DISCUSSION}

Epigenetic agents and in particular DNMTi and HDACi are under intense investigation for their use in cancer therapy [21]. Better understanding of the underlying molecular effects of these agents will facilitate the translation into the clinic. Here, we investigated the possible induction of a DDR by decitabine in MM and how this is affected by JNJ-585 and different DNA repair inhibitors.

Using a panel of HMCLs, we observed the induction of apoptosis in response to decitabine at different timepoints. In addition to the HMCLs, we also demonstrate significant anti-MM effects of decitabine using the 5T33MM model. Previous work already demonstrated a difference in sensitivity to decitabine using a broad panel of HMCLs [36]. We confirm that RPMI8226 and JJN3 cells display a rapid onset of apoptosis and thus a high sensitivity to decitabine. The effects on downstream apoptotic proteins were similar in OPM-2 and RPMI-8226 cells. Both cell lines displayed clear cleavage of caspase proteins and PARP-1 when significant amounts of apoptosis were detected. Simultaneously, pro-apoptotic BIM expression was elevated both at the transcriptional and translational level. This is in agreement with our previous study where we showed the epigenetic regulation of BIM in MM [29]. We also observed cleavage of antiapoptotic MCL-1 simultaneously with caspase cleavage. In human, three splice variants of MCL-1 have been described, namely the anti-apoptotic isoform MCL-1L and the pro-apoptotic isoforms MCL-1S and MCL-1ES. At the post-translational level, caspase-mediated MCL-1 cleavage has also been observed [37, 38]. This supports our results that MCL-1 cleavage is caspase-mediated. It is also in line with the observation of cleavage of MCL-1 upon AZA treatment in MM1.S cells [39].

One aspect that may determine sensitivity to decitabine is the rate of decitabine incorporation. BrdU incorporation can be used to evaluate import and incorporation of nucleosides necessary for DNA replication and DNA repair. We observed that RPMI-8226 and JJN3 cells incorporate more BrdU at basal conditions compared to OPM-2 and NCI-H929 cells. In analogy, decitabine incorporation will be higher in RPMI-8226 and JJN3 cells what may result in a faster accumulation of lethal levels of DNA damage compared to OPM-2 and NCI-H929 cells. Preceding apoptosis, a significant amount of cells accumulated in the G0/G1- or G2/Mphase upon decitabine treatment. This confirms earlier work showing the anti-proliferative effects of decitabine $[40,41]$. In addition, BrdU incorporation decreased upon decitabine exposure what correlates with the drop of cells in S-phase and the observed arrest. Cell cycle arrest by decitabine is often associated with p21 upregulation [40, 42]. However, the role of the CDK-inhibitor p 27 herein is less clear. In association with the cell cycle arrest, we observed an upregulation of p27. It has been described that p27 protein expression is stabilized in response to DNA damage and may be part of a DDR pathway related to the detrimental effects of continuous DNA damage [43]. Furthermore, we showed a simultaneous drop in SKP-2 expression. SKP-2 is responsible for p27 degradation [44], thereby explaining the observed accumulation of $\mathrm{p} 27$. This indicates that SKP-2 may be downregulated in response to decitabine-mediated DNA damage what results in p27 accumulation and subsequent cell cycle arrest. Indeed, earlier reports demonstrated SKP-2 downregulation and p27 accumulation in response to DNA damage $[45,46]$.

Our observation that decitabine increased the percentages of cells having more than 10 gamma-H2AX foci is in agreement with previous studies showing the DNA-damaging effects of DNMTi [17, 39, 40, 47]. Compared to melphalan, decitabine led to lower percentages of gamma-H2AX positive cells demonstrating that melphalan is more potent to induce DNA damage. Also at the basal level, we could already detect a fair amount of gamma-H2AX positive cells what is in line with a previous report showing constitutive DNA damage in MM [48]. Interestingly, the induction of gamma-H2AX positive cells by decitabine was similar between RPMI-8226 and OPM-2 cells and therefore cannot explain the earlier apoptosis induction in RPMI-8226 cells. This suggest that, not only the amount of gamma-H2AX positive cells per se, but also the ability to repair decitabine-induced DNA lesions determines if a cell will undergo apoptosis. HR has been implicated in the response towards DNA-protein cross links [16]. Furthermore, Orta et al. showed earlier that decitabine could induce both RAD51 and 53BP1 foci formation and proposed that HR governs protection while NHEJ results in accumulation of cytotoxic chromosome aberrations [17].Using 53BP1 and RAD51 as a marker for respectively NHEJ and HR, we demonstrate that OPM-2 and RPMI-8226 cells have a certain degree of basal activity of both repair pathways. Upon decitabine exposure, RAD51 foci formation remained at basal level in OPM-2 cells, indicating that decitabine did not stimulate signaling towards HR in OPM-2 cells. The lack of induction of RAD51 foci in OPM-2 cells was furthermore reflected by the accumulation of OPM- 2 cells in $\mathrm{G} 0 / \mathrm{G} 1$-phase after decitabine exposure. Concordantly, 53BP1 foci formation was induced by decitabine what reflects NHEJ stimulation in an attempt to repair most of the DNA damage. Nevertheless, as RAD51 positivity remained at basal level, part of the damage might be repaired by HR repair. This is further supported by the 
presence of approximately $20 \%$ S-phase (BrdU positive) cells. In contrast to OPM-2 cells, both 53BP1 and RAD51 foci formation was induced by decitabine in RPMI-8226 cells. Since these cells were arrested in G2/M-phase, both NHEJ and HR seemed to be stimulated and may thus compete with each other to repair DNA [12]. Given that NHEJ is more error-prone compared to HR, the balance between the two pathways may eventually determine the occurrence of (lethal) chromosome aberrations and thus cytotoxicity [17]. However, we have to note that abnormalities in different DNA repair pathways in different cell lines may determine which pathway is dominant over another and if DNA lesions are successfully repaired. For example, RPMI-8226 and to a lesser extent OPM-2 cells have impaired capacity to successfully complete NHEJ [14]. This impaired capacity may affect the accumulation of cytotoxic chromosomal aberrations.

Similar to previous studies, we observed that the combination between decitabine and the HDACi JNJ-585 had synergistic anti-MM effects which were associated with enhanced caspase, PARP-1 and MCL1 cleavage compared to either agent alone [25-28, 49]. We also confirmed the combinatory effects of decitabine and JNJ-585 in vivo. At the dose used in our study, JNJ-585 did not increase gamma-H2AX foci formation on itself, while the level of gamma-H2AX positivity between decitabine and the combination was similar. This prompted us to investigate how the DNA repair response towards decitabine is influenced in combination with JNJ585. In RPMI-8226 cells, JNJ-585 maintained RAD51 positivity at basal levels in response to decitabine while in OPM-2 cells JNJ-585 decreased RAD51 positivity below basal levels in combination with decitabine. In contrast, 53BP1 positivity was largely unchanged by JNJ585 in response to decitabine. This indicates that NHEJ activity remained stable in the combination conditions while HR activity decreased. The effects on cell cycle progression in the combination also support this. JNJ585 consistently induced a G0/G1-phase arrest. This arrest was stronger than for decitabine and was also sustained in the combination in OPM-2 and JJN3 cells. Importantly, at the time of the G0/G1-arrest, decitabineinduced DNA damage was already present as evidenced by the significant higher gamma- $\mathrm{H} 2 \mathrm{AX}$ formation in the combination. Thus, because of the G0/G1-arrest induction (after decitabine-mediated DNA damage) by JNJ-585 and/or the inhibitory effects on HR, it seems that the cells' repair capacity becomes more and more restricted to NHEJ. This then may result in a faster and stronger accumulation of chromosomal aberrations compared to decitabine alone, hence explaining the enhanced cytotoxic effects of the combination. Collectively, we report that JNJ-585 negatively influenced HR-mediated DNA repair in response to decitabine by inducing a G0/ G1-phase arrest, inhibiting RAD51 foci formation and/or downregulating expression of key HR genes. These effects likely shift the balance of DNA repair to NHEJ and are in favor of the hypothesis that DNA repair is a factor that determines the onset of apoptosis by decitabine. The effect of JNJ-585 on RAD51 are in line with results from others demonstrating that HDACi downregulate RAD51 in colon cancer and Chinese hamster ovary cells and inhibit irradiation-mediated RAD51 foci formation [50, 51]. In analogy, the HDACi SNDX-275 and LBH-589 have previously been shown to enhance cytotoxic effects of melphalan and doxorubicin in $\mathrm{MM}[52,53]$. Interestingly, the effects of JNJ-585 on HR genes are similar to what has been described for bortezomib, namely downregulation of HR-related genes (so called "BRCAness state) [54]. Our results imply that JNJ-585 may also be a candidate compound to interfere with HR-mediated DNA repair especially in combination with DNA damaging agents and point towards the HR pathway being a promising target to pursue for MM treatment [15].

Finally, we used the RAD51 specific inhibitor B02 to prove the role of RAD51 in decitabine-induced DDR. B02 alone was cytotoxic indicating that RAD51 is a potential target in MM, even in the absence of DNA damaging agents. Furthermore, B02 could sensitize both RPMI-8226 and OPM-2 cells to decitabine. This is in agreement with the effect of JNJ-585 and again indicates that by inhibiting RAD51, the repair balance may be shifted towards NHEJ leading to more cytotoxicity. Unexpectedly, ABT-888, sensitized RPMI-8226 but not OPM-2 cells to decitabine. ABT-888 (Veliparib) is a PARP1/2 inhibitor and is a promising agent in (pre-) clinical development for solid and hematological malignancies especially in combination with DNA damaging agents [35, 54-56]. PARP proteins are mainly implicated in single strand break repair but have been shown to be important for double strand break repair as well [57-59]. More specifically, PARP proteins promote HR by detecting collapsed replication forks and recruiting DNA repair factors important for HR [60]. In addition, both NHEJ-inhibiting and -promoting roles have been described for PARP $[61,62]$. Our observation that ABT-888 enhances decitabine-mediated apoptosis suggests that PARP1/2 protects cells from decitabineinduced DNA damage, possibly by inhibiting NHEJ [58].

Currently, clinical trials with HDACi are ongoing. In MM, panobinostat in combination with dexamethasone and bortezomib was recently shown to overcome bortezomib-resistance in relapsed/refractory MM patients [19, 63]. Another HDACi, vorinostat, in combination with bortezomib had also beneficial effects in refractory/ relapsed patients [18]. Furthermore, a dose escalation study with JNJ-585 (quisinostat) in combination with bortezomib and dexamethasone showed a good safety profile and clinical activity in relapsed MM patients [64]. However, no reports on clinical trials using decitabine in MM have been published, probably because of absence of significant clinical activity. This may be explained by the lack of decitabine incorporation in mature MM cells 
which in general have a low proliferation rate. However, proliferation is augmented in advanced stages and is considered a bad prognostic factor [65]. In addition, during normal development, plasma cells transit through an immature pre-plasmablast stage characterized by a high proliferation rate $[66,67]$. Recently, a similar MM subpopulation mediating therapeutic resistance to bortezomib has been identified in MM patients [68]. Thus, when proliferation is higher (ie. in advanced stages or in pre-plasmablasts), decitabine will probably be actively incorporated what may result in a clinical response, especially in combination with a HDACi or DNA repair inhibitors. Interestingly, Caraux et al. reported the existence of a residual MM cell population after high dose melphalan and autologous stem cell transplantation [69]. Further characterization of this MM population is desirable as it represents cells that survived induction therapy with bortezomib and dexamethasone as well as high-dose melphalan and transplantation. These cells thus may have an immature phenotype, a high proliferation rate and ongoing DNA repair activity. Therefore, the use of other DNA damaging agents such as decitabine and agents that interfere with DNA repair such as JNJ-585 or B02 may be useful to target this population at the right moment during therapy (ie. post-transplant). Furthermore, it has been suggested that plasticity between pre-plasma cells and plasma cells is epigenetically regulated and underlines clinical resistance [70]. Better understanding of this epigenetic program will be necessary to find out whether epigenetic modulating agents may be useful to elucidate key elements of this epigenetic program or may have a favorable effect on pre-plasma cell - plasma cell transition in terms of circumventing resistance.

In conclusion, we report that DNA damage plays an important role in the mechanisms of decitabine-mediated cytotoxicity in MM. Notably, decitabine is less potent than for example melphalan in inducing DNA damage but decitabine also has epigenetic effects, definitely in combination with HDACi. Furthermore, interfering with DNA repair pathways using HDACi or more specific DNA repair inhibitors appears a promising strategy to enhance decitabine-mediated cytotoxicity. A direct implication of the data is that deeper understanding of DNA repair processes in MM cells can lead to more targeted combinations with DNA damaging agents.

\section{MATERIAL AND METHODS}

\section{Cell Lines}

HMCLs were obtained from ATCC (Molsheim, France). RPMI-8226, OPM-2 and JJN3 were cultured in RPMI-1640 medium (Lonza, Basel, Switzerland) with 10\% FCS (Biochrom AG, Berlin, Germany) and supplements $(100 \mathrm{U} / \mathrm{ml}$ penicillin/streptomycin and $2 \mathrm{mM}$ L-glutamine (Lonza)). NCI-H929 cells were grown in RPMI-1640 medium with 20\% FCS (Biochrom $\mathrm{AG}$ ), supplements plus $1 \mathrm{mM}$ Na-Pyruvate (Lonza) and $55 \mu \mathrm{M} \beta$-mercaptoethanol (Sigma, Bornem, Belgium). Authenticity of HMCLs was regularly confirmed by shorttandem repeat analysis.

\section{Mice}

C57BL/KaLwRij mice were purchased from Harlan CPB (Horst, The Netherlands) and housed under conventional conditions. Mice were treated according to the conditions approved by the Ethical Committee for Animal Experiments of the Vrije Universiteit Brussel (license no. LA1230281).

\section{Compounds}

Decitabine (Dacogen) and JNJ-26481585 (quisinostat; JNJ-585) were kindly provided by Johnson \& Johnson (Beerse, Belgium). Melphalan and B02 were obtained at Sigma. ABT-888 was obtained from Selleckchem (Munich, Germany). Decitabine, JNJ-585, ABT-888 and B02 were dissolved in dimethylsulfoxide. Melphalan was dissolved in acidified ethanol. For in vivo experiments, decitabine and JNJ-585 were used as a filter sterilized $10 \%$ hydroxypropyl-cyclodextran suspension.

\section{Apoptosis assay}

Apoptosis was measured by flow cytometry (FACSCanto, BD Biosciences, Franklin Lakes, USA) using AnnexinV-FITC and 7'-aminoactinomycin D (7'AAD) (BD Biosciences) according to manufacturer's instructions. Results were analyzed using FACSDiva software (BD Biosciences).

\section{BrdU incorporation and cell cycle analysis}

Bromo-deoxyuridine (BrdU; 1mg/ml) (Roche Diagnostics, Vilvoorde, Belgium) was administered 2 hours prior to harvest. Next, cells were washed and fixed in paraformaldehyde overnight. The following day, cells were incubated with $\mathrm{HCl}$ and washed before anti-BrdUFITC antibody (Roche diagnostics) was added. Next, cells were washed and incubated with a propidium iodide (PI) solution containing 0.1\% Triton-X100 (Merck, Barmstadt, Germany), $1 \mathrm{mg} / \mathrm{ml}$ sodium nitrate (Merck), $100 \mu \mathrm{g} / \mathrm{ml}$ RNaseA (Boehringer Ingelheim, Germany) and 50 $\mathrm{g}$ / ml PI (Sigma). Cells were analyzed by flow cytometry (FACSCanto) using FACSDiva software. 


\section{Western blot}

Western blot was performed as described previously [29]. The antibodies used were all purchased from Cell Signaling (Bioké, Leiden, The Netherlands). The following clones of antibodies were used: caspase-3 (\#9665), caspase-9 (\#9502), caspase-8 (\#9746), BIM (C34C5, \#2933), MCL-1 (D35A5, \#5453), p27 (D37H1, \#3688), SKP-2 (L70, \#4313) and ACTIN (\#4967).

\section{Quantitative real-time PCR}

After indicated time-points, cells were harvested and RNA was extracted by the RNeasy mini kit (Qiagen, Venlo, The Netherlands). $1 \mu \mathrm{g}$ of total RNA was converted into cDNA using the First-strand cDNA synthesis kit (VWR International, Leuven, Belgium). Quantitative real-time PCR was performed and analyzed as previously described [29]. Primers for BRCA1, BRCA2 and RAD51 were purchased at Thermo Scientific (Aalst, Belgium) and ABL1 primers were bought at Integrated DNA Technologies (Leuven, Belgium). Primer sequences were as follows (5'3'): BRCA1: forward: ACCGTTGCTACCGAGTGTCTG; reverse: GTGATGTTCCTGAGATGCCTTTGC; BRCA2: forward: AACCGTGTGGAAGTTGCGTA TTG; reverse: GGCTCCCGTGGCTGGTAAATC; RAD51: forward: TCAAGTGGATG GAGCAGCGATG; reverse: TGGCAGTCACAACAGGAAGAGG. ABL1: forward: TTGTGGCCAGTGGAGATAAC; reverse: GTTTGGGCTTCACACCATTC.

\section{Immunofluorescence staining and microscopy}

Cells were plated at a density of $20.000 / \mathrm{ml}$ three days before treatment. After indicated timepoints, cytospins were made and stored at $-20^{\circ} \mathrm{C}$. The staining protocol was as follows: cytospins were fixed in $4 \%$ paraformaldehyde and washed with Tris- $\mathrm{NaCl} 0.05 \%$ Triton-X100 (Merck). Next, cytospins were blocked by $2 \%$ donkey serum and incubated overnight with the primary antibodies; gamma-H2AX (20E3, \#9718; Bioké), RAD51 (ABE257; Millipore, Overijse, Belgium), 53BP1 (100-304; Novus Biologicals, Cambridge, UK). Next, cytospins were washed and incubated for 1 hour with donkey anti-rabbit-FITC (Jackson ImmunoResearch, St-Martens-Latem, Belgium). After washing, cytospins were mounted with Vectashield (Thermo Scientific) containing 4,6-diamidino-2-phenylindole (DAPI). Immunofluorescence was observed using a Nikon Eclipse $90 \mathrm{i}$ with a $60 \mathrm{X}$ objective magnification. Pictures were taken using a Nikon DS-Ril and analyzed using the ImageJ macro PZ-FociEZ. Briefly, DAPI was used to define the nuclei. Next, foci were counted in the nuclei by analyzing local maxima in fluorescence intensity. At least
100 nuclei were analyzed and nuclei with at least 10 foci were scored as positive.

\section{Prophylactic treatment of 5T33MM mice}

The 5T33MM model was maintained as previously described [30]. At day 0, naive C57BL/KaLwRij mice were intravenously injected with $5 \times 10^{5} \quad 5 \mathrm{~T} 33 \mathrm{MM}$ cells. Mice were treated with decitabine starting at day 1 (intraperitoneal injection, 6 days/week). For the combination experiment, JNJ-585 was administered subcutaneously at $1.5 \mathrm{mg} / \mathrm{kg}$ once every other day. Mice were sacrified after 3 weeks, when vehicle treated 5T33MM mice showed clear signs of morbidity (hind limb paralysis). For the survival study, the treatment schedule continued until each individual animal showed signs of morbidity. Blood was collected for serum M-spike determination and $\mathrm{BM}$ was isolated from hind legs to quantify tumor burden as previously described [31].

\section{Graphical analysis and statistics}

Graphical and statistical analyses were done using Sigmaplot 11.0 (Systat software Inc., San Jose, USA). Student t-test or Mann-Whitney test was used to compare parametric or non-parametric data, respectively. Survival curves were created by Kaplan-Meier analysis. Survival probabilities were compared by a log-rank test. P values of $<0.05$ were considered statistically significant.

\section{Conflict of interest}

Steve Mcclue works for Janssen, Pharmaceutical Companies of Johnson \& Johnson. The other authors declare no potential conflict of interest.

\section{ACKNOWLEDGEMENTS}

We thank Carine Seynaeve, Marie Joost de ter Beest, Jordan Gauthier and Angelo Willems for their expert technical assistance. We thank Prof. Frans Gorus and the laboratory for clinical chemistry (UZ Brussel) for serum M-spike measurements. Decitabine and JNJ26481585 were kindly provided by Johnson \& Johnson (Beerse, Belgium).

The work was financially supported by the Fonds voor Wetenschappelijk Onderzoek Vlaanderen (FWO-Vl), the Belgische Federatie tegen Kanker, King Baudouin Foundation, Vlaamse Liga tegen Kanker and the Onderzoeksraad Vrije Universiteit Brussel (GOA48, OZRVUB). E. Menu, E. Van Valckenborgh and E. De Bruyne are postdoctoral fellows of FWO-Vl. 


\section{REFERENCES}

1. Mahindra A, Hideshima T and Anderson KC. Multiple myeloma: biology of the disease. Blood Rev. 2011; 24 Suppl 1: S5-11.

2. Engelhardt M, Terpos E, Kleber M, Gay F, Wasch R, Morgan G, Cavo M, van de Donk N, Beilhack A, Bruno B, Johnsen HE, Hajek R, Driessen C, et al. European Myeloma Network recommendations on the evaluation and treatment of newly diagnosed patients with multiple myeloma. Haematologica. 2014; 99: 232-242.

3. Facon T, Mary JY, Hulin C, Benboubker L, Attal M, Pegourie B, Renaud M, Harousseau JL, Guillerm G, Chaleteix C, Dib M, Voillat L, Maisonneuve H, et al. Melphalan and prednisone plus thalidomide versus melphalan and prednisone alone or reduced-intensity autologous stem cell transplantation in elderly patients with multiple myeloma (IFM 99-06): a randomised trial. Lancet. 2007; 370: 1209-1218.

4. Harousseau JL, Attal M, Avet-Loiseau H, Marit G, Caillot D, Mohty M, Lenain P, Hulin C, Facon T, Casassus $\mathrm{P}$, Michallet M, Maisonneuve H, Benboubker L, et al. Bortezomib plus dexamethasone is superior to vincristine plus doxorubicin plus dexamethasone as induction treatment prior to autologous stem-cell transplantation in newly diagnosed multiple myeloma: results of the IFM 2005-01 phase III trial. J Clin Oncol. 2010; 28: 4621-4629.

5. Leleu X, Attal M, Arnulf B, Moreau P, Traulle C, Marit G, Mathiot C, Petillon MO, Macro M, Roussel M, Pegourie B, Kolb B, Stoppa AM, et al. Pomalidomide plus low-dose dexamethasone is active and well tolerated in bortezomib and lenalidomide-refractory multiple myeloma: Intergroupe Francophone du Myelome 2009-02. Blood. 2013; 121: 1968-1975.

6. Roussel M, Facon T, Moreau P, Harousseau JL and Attal M. Firstline treatment and maintenance in newly diagnosed multiple myeloma patients. Recent Results Cancer Res. 2011; 183: 189-206.

7. Sonneveld P, Schmidt-Wolf IG, van der Holt B, El Jarari L, Bertsch U, Salwender H, Zweegman S, Vellenga E, Broyl A, Blau IW, Weisel KC, Wittebol S, Bos GM, et al. Bortezomib induction and maintenance treatment in patients with newly diagnosed multiple myeloma: results of the randomized phase III HOVON-65/ GMMG-HD4 trial. J Clin Oncol. 2012; 30: 2946-2955.

8. Usmani SZ, Crowley J, Hoering A, Mitchell A, Waheed S, Nair B, AlSayed Y, Vanrhee F and Barlogie B. Improvement in long-term outcomes with successive Total Therapy trials for multiple myeloma: are patients now being cured? Leukemia. 2013; 27: 226-232.

9. Sharma S, Kelly TK and Jones PA. Epigenetics in cancer. Carcinogenesis. 2010; 31: 27-36.

10. Maes K, Menu E, Van Valckenborgh E, Van Riet I, Vanderkerken $\mathrm{K}$ and De Bruyne E. Epigenetic modulating agents as a new therapeutic approach in multiple myeloma.
Cancers. 2013; 5: 430-461.

11. Stresemann C and Lyko F. Modes of action of the DNA methyltransferase inhibitors azacytidine and decitabine. Int J Cancer. 2008; 123: 8-13.

12. Lord CJ and Ashworth A. The DNA damage response and cancer therapy. Nature. 2012; 481: 287-294.

13. Gourzones-Dmitriev C, Kassambara A, Sahota S, Reme T, Moreaux J, Bourquard P, Hose D, Pasero P, Constantinou A and Klein B. DNA repair pathways in human multiple myeloma: role in oncogenesis and potential targets for treatment. Cell Cycle. 2013; 12: 2760-2773.

14. Yang C, Betti C, Singh S, Toor A and Vaughan A. Impaired NHEJ function in multiple myeloma. Mutat Res. 2009; 660: 66-73.

15. Shammas MA, Shmookler Reis RJ, Koley H, Batchu RB, Li C and Munshi NC. Dysfunctional homologous recombination mediates genomic instability and progression in myeloma. Blood. 2009; 113: 2290-2297.

16. Nakano T, Katafuchi A, Matsubara M, Terato H, Tsuboi T, Masuda T, Tatsumoto T, Pack SP, Makino K, Croteau DL, Van Houten B, Iijima K, Tauchi H, et al. Homologous recombination but not nucleotide excision repair plays a pivotal role in tolerance of DNA-protein cross-links in mammalian cells. J Biol Chem. 2009; 284: 27065-27076.

17. Orta ML, Calderon-Montano JM, Dominguez I, Pastor N, Burgos-Moron E, Lopez-Lazaro M, Cortes F, Mateos S and Helleday T. 5-Aza-2'-deoxycytidine causes replication lesions that require Fanconi anemia-dependent homologous recombination for repair. Nucleic Acids Res. 2013; 41: 5827-5836.

18. Dimopoulos M, Siegel DS, Lonial S, Qi J, Hajek R, Facon T, Rosinol L, Williams C, Blacklock H, Goldschmidt H, Hungria V, Spencer A, Palumbo A, et al. Vorinostat or placebo in combination with bortezomib in patients with multiple myeloma (VANTAGE 088): a multicentre, randomised, double-blind study. Lancet Oncol. 2013; 14: 1129-1140.

19. Richardson PG, Schlossman RL, Alsina M, Weber DM, Coutre SE, Gasparetto C, Mukhopadhyay S, Ondovik MS, Khan M, Paley CS and Lonial S. PANORAMA 2: panobinostat in combination with bortezomib and dexamethasone in patients with relapsed and bortezomibrefractory myeloma. Blood. 2013; 122: 2331-2337.

20. Robert T, Vanoli F, Chiolo I, Shubassi G, Bernstein KA, Rothstein R, Botrugno OA, Parazzoli D, Oldani A, Minucci $\mathrm{S}$ and Foiani M. HDACs link the DNA damage response, processing of double-strand breaks and autophagy. Nature. 2011; 471: 74-79.

21. Boumber Y and Issa JP. Epigenetics in cancer: what's the future? Oncology (Williston Park). 2011; 25: 220-226, 228.

22. Mercurio C, Minucci S and Pelicci PG. Histone deacetylases and epigenetic therapies of hematological malignancies. Pharmacol Res. 2010; 62: 18-34.

23. Heller G, Schmidt WM, Ziegler B, Holzer S, Mullauer L, 
Bilban M, Zielinski CC, Drach J and Zochbauer-Muller S. Genome-wide transcriptional response to 5-aza-2'deoxycytidine and trichostatin a in multiple myeloma cells. Cancer Res. 2008; 68: 44-54.

24. Steele N, Finn P, Brown R and Plumb JA. Combined inhibition of DNA methylation and histone acetylation enhances gene re-expression and drug sensitivity in vivo. Br J Cancer. 2009; 100: 758-763.

25. Brodska B and Holoubek A. Generation of reactive oxygen species during apoptosis induced by DNA-damaging agents and/or histone deacetylase inhibitors. Oxid Med Cell Longev. 2011; 2011: 253529-253535.

26. Brodska B, Otevrelova P and Holoubek A. Decitabineinduced apoptosis is derived by Puma and Noxa induction in chronic myeloid leukemia cell line as well as in PBL and is potentiated by SAHA. Mol Cell Biochem. 2011; 350: 7180 .

27. Chen MY, Liao WS, Lu Z, Bornmann WG, Hennessey V, Washington MN, Rosner GL, Yu Y, Ahmed AA and Bast RC, Jr. Decitabine and suberoylanilide hydroxamic acid (SAHA) inhibit growth of ovarian cancer cell lines and xenografts while inducing expression of imprinted tumor suppressor genes, apoptosis, G2/M arrest, and autophagy. Cancer. 2011; 117: 4424-4438.

28. Nishioka C, Ikezoe T, Yang J, Udaka K and Yokoyama A. Simultaneous inhibition of DNA methyltransferase and histone deacetylase induces p53-independent apoptosis via down-regulation of Mcl-1 in acute myelogenous leukemia cells. Leuk Res. 2011; 35: 932-939.

29. De Bruyne E, Bos TJ, Schuit F, Van Valckenborgh E, Menu E, Thorrez L, Atadja P, Jernberg-Wiklund H and Vanderkerken K. IGF-1 suppresses Bim expression in multiple myeloma via epigenetic and posttranslational mechanisms. Blood. 2010; 115: 2430-2440.

30. Asosingh K, Radl J, Van Riet I, Van Camp B and Vanderkerken K. The 5TMM series: a useful in vivo mouse model of human multiple myeloma. Hematol J. 2000; 1: 351-356.

31. Deleu S, Lemaire M, Arts J, Menu E, Van Valckenborgh E, King P, Vande Broek I, De Raeve H, Van Camp B, Croucher $\mathrm{P}$ and Vanderkerken K. The effects of JNJ26481585, a novel hydroxamate-based histone deacetylase inhibitor, on the development of multiple myeloma in the 5T2MM and 5T33MM murine models. Leukemia. 2009; 23: 1894-1903.

32. Besson A, Dowdy SF and Roberts JM. CDK inhibitors: cell cycle regulators and beyond. Dev Cell. 2008; 14: 159-169.

33. Huang F, Motlekar NA, Burgwin CM, Napper AD, Diamond SL and Mazin AV. Identification of specific inhibitors of human RAD51 recombinase using highthroughput screening. ACS Chem Biol. 2011; 6: 628-635.

34. Huang F, Mazina OM, Zentner IJ, Cocklin S and Mazin $\mathrm{AV}$. Inhibition of homologous recombination in human cells by targeting RAD51 recombinase. J Med Chem. 2012;
55: 3011-3020.

35. Donawho CK, Luo Y, Luo Y, Penning TD, Bauch JL, Bouska JJ, Bontcheva-Diaz VD, Cox BF, DeWeese TL, Dillehay LE, Ferguson DC, Ghoreishi-Haack NS, Grimm DR, et al. ABT-888, an orally active poly(ADP-ribose) polymerase inhibitor that potentiates DNA-damaging agents in preclinical tumor models. Clin Cancer Res. 2007; 13: 2728-2737.

36. Moreaux J, Reme T, Leonard W, Veyrune JL, Requirand G, Goldschmidt H, Hose D and Klein B. Development of gene expression-based score to predict sensitivity of multiple myeloma cells to DNA methylation inhibitors. Mol Cancer Ther. 2012; 11: 2685-2692.

37. Kim JH, Sim SH, Ha HJ, Ko JJ, Lee K and Bae J. MCL1ES, a novel variant of MCL-1, associates with MCL-1L and induces mitochondrial cell death. FEBS Lett. 2009; 583: 2758-2764.

38. Le Gouill S, Podar K, Harousseau JL and Anderson KC. Mcl-1 regulation and its role in multiple myeloma. Cell Cycle. 2004; 3: 1259-1262.

39. Kiziltepe T, Hideshima T, Catley L, Raje N, Yasui H, Shiraishi N, Okawa Y, Ikeda H, Vallet S, Pozzi S, Ishitsuka K, Ocio EM, Chauhan D, et al. 5-Azacytidine, a DNA methyltransferase inhibitor, induces ATR-mediated DNA double-strand break responses, apoptosis, and synergistic cytotoxicity with doxorubicin and bortezomib against multiple myeloma cells. Mol Cancer Ther. 2007; 6: 17181727.

40. Jiemjit A, Fandy TE, Carraway H, Bailey KA, Baylin S, Herman JG and Gore SD. p21(WAF1/CIP1) induction by 5-azacytosine nucleosides requires DNA damage. Oncogene. 2008; 27: 3615-3623.

41. Lavelle D, DeSimone J, Hankewych M, Kousnetzova T and Chen YH. Decitabine induces cell cycle arrest at the G1 phase via $\mathrm{p} 21$ (WAF1) and the G2/M phase via the p38 MAP kinase pathway. Leuk Res. 2003; 27: 999-1007.

42. Shin DY, Sung Kang H, Kim GY, Kim WJ, Yoo YH and Choi YH. Decitabine, a DNA methyltransferases inhibitor, induces cell cycle arrest at G2/M phase through p53-independent pathway in human cancer cells. Biomed Pharmacother. 2013; 67: 305-311.

43. Cuadrado M, Gutierrez-Martinez P, Swat A, Nebreda $\mathrm{AR}$ and Fernandez-Capetillo O. p27Kip1 stabilization is essential for the maintenance of cell cycle arrest in response to DNA damage. Cancer Res. 2009; 69: 8726-8732.

44. Carrano A, Eytan E, Hershko A and Pagano M. SKP2 is required for ubiquitin-mediated degradation of the $\mathrm{CDK}$ inhibitor p27. Nat Cell Biol. 1999; 1: 193-199.

45. Roe JS, Kim HR, Hwang IY, Cho EJ and Youn HD. von Hippel-Lindau protein promotes Skp2 destabilization on DNA damage. Oncogene. 2011; 30: 3127-3138.

46. Sugihara E, Kanai M, Saito S, Nitta T, Toyoshima H, Nakayama K, Nakayama KI, Fukasawa K, Schwab M, Saya $\mathrm{H}$ and Miwa M. Suppression of centrosome amplification 
after DNA damage depends on p27 accumulation. Cancer Res. 2006; 66: 4020-4029.

47. Palii SS, Van Emburgh BO, Sankpal UT, Brown KD and Robertson KD. DNA methylation inhibitor 5-Aza2'-deoxycytidine induces reversible genome-wide DNA damage that is distinctly influenced by DNA methyltransferases 1 and 3B. Mol Cell Biol. 2008; 28: 752771.

48. Walters $\mathrm{DK}, \mathrm{Wu} \mathrm{X}$, Tschumper RC, Arendt BK, Huddleston PM, Henderson KJ, Dispenzieri A and Jelinek DF. Evidence for ongoing DNA damage in multiple myeloma cells as revealed by constitutive phosphorylation of H2AX. Leukemia. 2011; 25: 1344-1353.

49. Chen G, Wang Y, Huang H, Lin F, Wu D, Sun A, Chang $\mathrm{H}$ and Feng Y. Combination of DNA methylation inhibitor 5 -azacytidine and arsenic trioxide has synergistic activity in myeloma. Eur J Haematol. 2009; 82: 176-183.

50. Adimoolam S, Sirisawad M, Chen J, Thiemann P, Ford JM and Buggy JJ. HDAC inhibitor PCI-24781 decreases RAD51 expression and inhibits homologous recombination. Proc Natl Acad Sci U S A. 2007; 104: 19482-19487.

51. Chen X, Wong P, Radany EH, Stark JM, Laulier C and Wong JY. Suberoylanilide hydroxamic acid as a radiosensitizer through modulation of RAD51 protein and inhibition of homology-directed repair in multiple myeloma. Mol Cancer Res. 2012; 10: 1052-1064.

52. Lee CK, Wang S, Huang X, Ryder J and Liu B. HDAC inhibition synergistically enhances alkylator-induced DNA damage responses and apoptosis in multiple myeloma cells. Cancer Lett. 2010; 296: 233-240.

53. Sanchez E, Shen J, Steinberg J, Li M, Wang C, Bonavida B, Chen H, Li ZW and Berenson JR. The histone deacetylase inhibitor LBH589 enhances the anti-myeloma effects of chemotherapy in vitro and in vivo. Leuk Res. 2010; 35: 373-379.

54. Neri P, Ren L, Gratton K, Stebner E, Johnson J, Klimowicz A, Duggan P, Tassone P, Mansoor A, Stewart DA, Lonial S, Boise LH and Bahlis NJ. Bortezomib-induced "BRCAness" sensitizes multiple myeloma cells to PARP inhibitors. Blood. 2011; 118: 6368-6379.

55. Clark CC, Weitzel JN and O'Connor TR. Enhancement of synthetic lethality via combinations of ABT-888, a PARP inhibitor, and carboplatin in vitro and in vivo using BRCA1 and BRCA2 isogenic models. Mol Cancer Ther. 2012; 11: 1948-1958.

56. Shunkwiler L, Ferris $\mathrm{G}$ and Kunos C. Inhibition of Poly(ADP-Ribose) Polymerase Enhances Radiochemosensitivity in Cancers Proficient in DNA Double-Strand Break Repair. Int J Mol Sci. 2013; 14: 37733785.

57. Chen A. PARP inhibitors: its role in treatment of cancer. Chin J Cancer. 2011; 30: 463-471.

58. De Lorenzo SB, Patel AG, Hurley RM and Kaufmann SH. The Elephant and the Blind Men: Making Sense of PARP
Inhibitors in Homologous Recombination Deficient Tumor Cells. Front Oncol. 2013; 3: 228.

59. Pears CJ, Couto CA, Wang HY, Borer C, Kiely R and Lakin ND. The role of ADP-ribosylation in regulating DNA double-strand break repair. Cell Cycle. 2012; 11: 48-56.

60. Bryant HE, Petermann E, Schultz N, Jemth AS, Loseva O, Issaeva N, Johansson F, Fernandez S, McGlynn P and Helleday T. PARP is activated at stalled forks to mediate Mre11-dependent replication restart and recombination. Embo J. 2009; 28: 2601-2615.

61. Couto CA, Wang HY, Green JC, Kiely R, Siddaway $\mathrm{R}$, Borer C, Pears CJ and Lakin ND. PARP regulates nonhomologous end joining through retention of $\mathrm{Ku}$ at double-strand breaks. J Cell Biol. 2011; 194: 367-375.

62. Wang $\mathrm{M}, \mathrm{Wu} \mathrm{W}, \mathrm{Wu} \mathrm{W}$, Rosidi B, Zhang L, Wang $\mathrm{H}$ and Iliakis G. PARP-1 and $\mathrm{Ku}$ compete for repair of DNA double strand breaks by distinct NHEJ pathways. Nucleic Acids Res. 2006; 34: 6170-6182.

63. Moreau P. Panobinostat to revert bortezomib resistance. Blood. 2013; 122: 2292-2293.

64. Moreau P, Facon T, Touzeau C, Benboubker L, Delain M, Badamo-Dotzis J, Phelps C, Doty C, Smit H, Fourneau $\mathrm{N}$, Forslund A, Hellemans P and Leleu X. Phase 1b Dose Escalation Study Of Oral Quisinostat, a Histone Deacetylase Inhibitor (HDACi), In Combination With Velcade (Bortezomib) and Dexamethasone For Patients With Relapsed Multiple Myeloma (MM). Blood. 2013; 122: 1932.

65. Hose D, Reme T, Hielscher T, Moreaux J, Messner T, Seckinger A, Benner A, Shaughnessy JD, Jr., Barlogie B, Zhou Y, Hillengass J, Bertsch U, Neben K, et al. Proliferation is a central independent prognostic factor and target for personalized and risk-adapted treatment in multiple myeloma. Haematologica. 2011; 96: 87-95.

66. Jourdan M, Caraux A, Caron G, Robert N, Fiol G, Reme T, Bollore K, Vendrell JP, Le Gallou S, Mourcin F, De Vos J, Kassambara A, Duperray C, et al. Characterization of a transitional preplasmablast population in the process of human B cell to plasma cell differentiation. J Immunol. 2011; 187: 3931-3941.

67. Jourdan M, Caraux A, De Vos J, Fiol G, Larroque M, Cognot C, Bret C, Duperray C, Hose D and Klein B. An in vitro model of differentiation of memory $B$ cells into plasmablasts and plasma cells including detailed phenotypic and molecular characterization. Blood. 2009; 114: 51735181.

68. Leung-Hagesteijn C, Erdmann N, Cheung G, Keats JJ, Stewart AK, Reece DE, Chung KC and Tiedemann RE. $\mathrm{Xbp} 1 \mathrm{~s}$-negative tumor B cells and pre-plasmablasts mediate therapeutic proteasome inhibitor resistance in multiple myeloma. Cancer Cell. 2013; 24: 289-304.

69. Caraux A, Vincent L, Bouhya S, Quittet P, Moreaux J, Requirand G, Veyrune JL, Olivier G, Cartron G, Rossi $\mathrm{JF}$ and Klein B. Residual malignant and normal plasma 
cells shortly after high dose melphalan and stem cell transplantation. Highlight of a putative therapeutic window in Multiple Myeloma? Oncotarget. 2012; 3: 1335-1347.

70. Chaidos A, Barnes CP, Cowan G, May PC, Melo V, Hatjiharissi E, Papaioannou M, Harrington H, Doolittle $\mathrm{H}$, Terpos E, Dimopoulos M, Abdalla S, Yarranton H, et al. Clinical drug resistance linked to interconvertible phenotypic and functional states of tumor-propagating cells in multiple myeloma. Blood. 2012; 121: 318-328. 